\title{
Persistent acceleration in global sea-level rise since the 1960s
}

\author{
Sönke Dangendorf $\oplus^{1,2 \star}$, Carling Hay ${ }^{3}$, Francisco M. Calafat $\oplus^{4}{ }^{4}$, Marta Marcos $\oplus^{5}$, \\ Christopher G. Piecuch ${ }^{6}$, Kevin Berk ${ }^{7}$ and Jürgen Jensen ${ }^{1}$
}

Previous studies reconstructed twentieth-century global mean sea level (GMSL) from sparse tide-gauge records to understand whether the recent high rates obtained from satellite altimetry are part of a longer-term acceleration. However, these analyses used techniques that can only accurately capture either the trend or the variability in GMSL, but not both. Here we present an improved hybrid sea-level reconstruction during 1900-2015 that combines previous techniques at time scales where they perform best. We find a persistent acceleration in GMSL since the 1960s and demonstrate that this is largely ( 76\%) associated with sea-level changes in the Indo-Pacific and South Atlantic. We show that the initiation of the acceleration in the 1960s is tightly linked to an intensification and a basin-scale equatorward shift of Southern Hemispheric westerlies, leading to increased ocean heat uptake, and hence greater rates of GMSL rise, through changes in the circulation of the Southern Ocean.

U nderstanding twentieth-century global and regional sealevel changes is of paramount importance, as they reflect both natural and anthropogenic changes occurring in the Earth's climate system (through changes in land-ice and ocean heat uptake) and affect the livelihood of hundreds of millions of people in the world's coastal regions. Satellite altimetry shows that GMSL has been rising at an average rate of about $3.1 \pm 0.3 \mathrm{~mm} \mathrm{yr}^{-1}$ since 1993, whereas complementary observations from profiling floats (observing density changes in the upper $2,000 \mathrm{~m}$ of the ocean) and gravimetric satellites (measuring mass changes from space) have enabled the attribution of the GMSL signal to its density and mass contributions with an accuracy of $\sim 0.3 \mathrm{~mm} \mathrm{yr}^{-1}$ since about 2005 $\left(\right.$ ref. $\left.{ }^{1}\right)$. Recent altimetry-based studies also report that the pace of GMSL has been accelerating since 1993 (refs. ${ }^{2-4}$ ), which is consistent with independent estimates of increasing mass contributions from Greenland and Antarctica over the last two decades ${ }^{5,6}$. However, when this acceleration started and what processes contributed the most to it remains unclear, as satellite altimetry only covers the short period since 1993. A complementary source of sea-level information comes from the network of tide gauges. Although confined to the coast and containing data gaps, tide-gauge records in some places date back to the Industrial Revolution. Synthesizing the tidegauge record with satellite altimetry requires statistical techniques that allow for sparse data coverage and the treatment of systematic differences between the two observing systems ${ }^{7-9}$.

Several approaches have been developed to reconstruct the geometry of past sea-level change with similar spatial coverage as satellite altimetry and spanning the same period as the tide-gauge record ${ }^{10-12}$. These can roughly be divided into two types of approaches: probabilistic techniques based on the Kalman Smoother (KS) or Gaussian Process Regression ${ }^{12-14}$, which fit known spatial patterns of individual sea-level contributors ${ }^{15}$, also known as fingerprints, to tide-gauge records, and Reduced Space Optimal Interpolation (RSOI) techniques, which reconstruct the temporal amplitudes of a truncated set of empirical orthogonal functions (EOFs) calculated from satellite altimetry using tide-gauge data ${ }^{10,11,16}$. Probabilistic techniques provide robust and smooth reconstructions of longterm changes in sea level (including more realistic modelling of uncertainties) even if only a few tide gauges are available ${ }^{12-14}$, but in their current set-up they fail in realistically reconstructing the interannual variability ${ }^{17}$. RSOI reconstructions, on the other hand, are generally capable of reconstructing interannual to decadal sealevel changes ${ }^{18-20}$, although they have their limitations in accurately estimating long-term trends ${ }^{14}$. Consequently, while both groups of techniques have their individual advantages, neither is (as currently configured) able to reconstruct the full spectrum of global and regional sea-level change ${ }^{18}$. This conundrum contributes to the large differences between individual reconstructions before the $1970 \mathrm{~s}^{21,22}$ and therefore hampers placing the recent acceleration into the historical context of the twentieth century.

Our aim here is to combine low-frequency sea-level information from the $\mathrm{KS}^{12}$ with high-frequency information from RSOI reconstructions to generate a hybrid reconstruction (HR) of global and regional sea-level during 1900-2015, which uses the techniques only at those time scales where they perform best. This is achieved by taking the low-frequency signal of the KS reconstruction (smoothed with a cut-off period of 15 years) at individual sites as a trend correction for each tide-gauge record. The residuals (with spectral power remaining at periods below 15 years) are then used in an iterative RSOI reconstruction with similarly detrended satellite altimetry data (see also Supplementary Fig. 1). The latter step also includes a gap-filling algorithm based on stepwise regression models with surface wind stress, sea-level pressure (SLP), sea surface temperature (SST), and neighbouring sites as predictors for minimizing gap-induced biases in the RSOI reconstruction (see Methods). Combining the low-frequency KS field with the high-frequency residual RSOI reconstruction provides a novel HR including high latitudes in the Arctic Ocean and around Antarctica. The HR of GMSL presented is based on the assimilation of 479 carefully selected tide-gauge records (see Methods). 
a

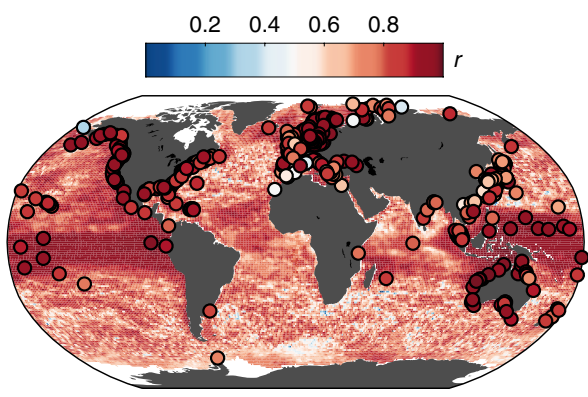

b

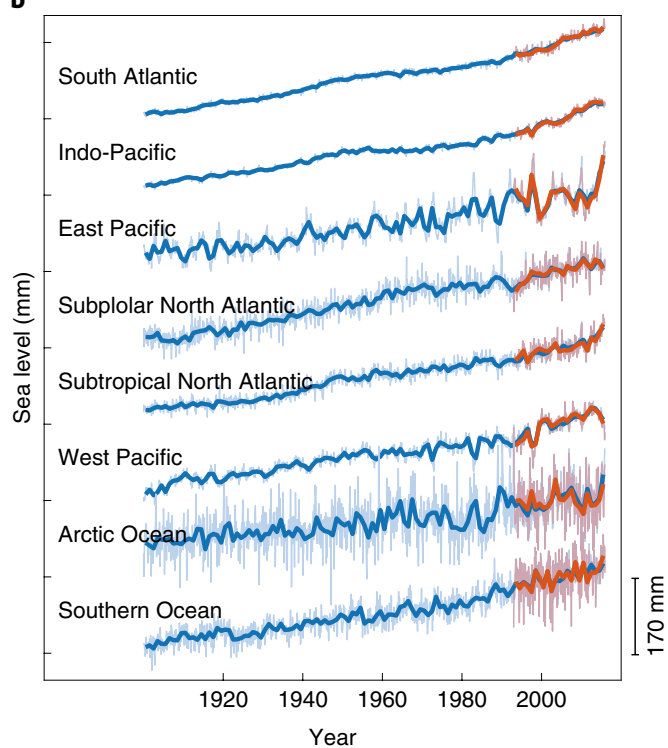

Fig. 1 Performance of the HR in comparison to satellite altimetry and tide gauges. a, Correlation between the GIA-corrected relative sea level from HR and satellite altimetry during 1993-2015 (shading) and the HR and tide gauges (black circles) during their overlapping periods. Correlations have been calculated on the basis of annual detrended time series. $\mathbf{b}$, Basin-scale averages from the hybrid reconstruction (blue) and satellite altimetry (red). Thin lines show monthly means while thick lines mark annual averages.

\section{Validation and comparison to former reconstructions}

Comparing the annual HR with individual tide-gauge observations yields excellent agreement at most sites, with a median correlation of $r=0.85$ (for detrended time series) (Fig. 1 a and Supplementary Fig. 2). This result is robust at independent validation sites that have not been used in the HR ( $r=0.79$; Supplementary Fig. 3$)$ and persists at decadal time scales (Supplementary Fig. 4). The strong correlations also reflect a major improvement in terms of the representation of interannual variability over the KS and RSOI used as stand-alone approaches with the same tide-gauge network as input showing median correlations of $r=0.46$ and $r=0.72$ (Supplementary Fig. 5a), respectively. In total there are only seven out of the initial 479 sites with non-significant correlations (that is $P>0.05$, see Methods), from which almost all are surrounded by nearby gauges showing significantly larger correlations, suggesting local issues with those few tide gauges and not any deficiencies in the reconstruction itself. Similar high correlations (median $r=0.80$ compared to median $r=0.73$ with the classical RSOI approach (Supplementary Fig. 5a)) are also found when comparing the HR (after removing the contribution of glacial isostatic adjustment (GIA), see Methods) to satellite altimetry at individual grid points (Fig. 1a). The correlations are slightly smaller in eddy-rich regions (for example, along major western boundary currents and their extensions); small-scale variability in these regions is poorly represented by the RSOI approach and aliased by tide gauges. However, spatial averaging over basin-scale regions of coherent sea-level variation ${ }^{23}$ (Fig. 1b) reveals correlations that are generally larger than $r=0.87$ (Table 1). Only over the Southern Ocean around Antarctica do we find a slightly weaker performance $(r=0.75)$. Maximum correlations of $r=0.98$ and $r=0.97$ are observed in the East Pacific and IndoPacific regions, respectively (Fig. $1 \mathrm{~b}$ and Table 1). This agreement could reflect large-scale forcing by wind stress associated with natural climate modes (for example, El Niño/Southern Oscillation (ENSO) and the Indian Ocean Dipole) and the ocean's attendant dynamic response through Kelvin and Rossby waves ${ }^{24,25}$, which dominates the EOFs of altimetric sea level used in the HR.

We also compare the GMSL of our HR to satellite altimetry observations and find good agreement between the two data sets. This holds for both the interannual variability $(r=0.95)$ and also for linear $\left(2.9 \pm 0.2 \mathrm{~mm} \mathrm{yr}^{-1}\right.$ (1 s.e.m., see Methods) and $2.9 \pm 0.1 \mathrm{~mm} \mathrm{yr}^{-1}$ for drift-corrected satellite altimetry (see Methods) and the HR, respectively) (Table 1) and quadratic trends $\left(0.08 \pm 0.02 \mathrm{~mm} \mathrm{yr}^{-2}\right.$ and $\left.0.09 \pm 0.03 \mathrm{~mm} \mathrm{yr}^{-2}\right)$ over their overlapping period 1993-2015, further demonstrating the improved performance of the HR in terms of both trends and variability compared to earlier assessments ${ }^{22}$.

\section{Tracking the recent GMSL acceleration back in time}

The GMSL from the HR (after removing the GIA signal) over the entire period of 1900-2015 (Fig. 2a and a comparison to former reconstructions can be found in Supplementary Fig. 5a) is characterized by an average trend (here derived as a temporal average of the rates from a singular system analysis (SSA) with an embedding dimension of 10 years) of approximately $1.6 \pm 0.4 \mathrm{~mm} \mathrm{yr}^{-1}$ (Table 1 ), whereby the rates are characterized by a considerable multi-decadal variability (Fig. 2b). Over the recent satellite period the GMSL rate increases by $\sim 1.3 \mathrm{~mm} \mathrm{yr}^{-1}$ from $1993\left(2.1 \pm 0.1 \mathrm{~mm} \mathrm{yr}^{-1}\right)$ to 2015 $\left(3.4 \pm 0.3 \mathrm{~mm} \mathrm{yr}^{-1}\right)$. This is qualitatively consistent with the driftcorrected altimeter record from AVISO (Fig. 2b) and the estimate by ref. ${ }^{3}$ obtained with different statistical techniques. However, by looking further back in time we see that this recent increase in the rate of rise is not a unique phenomenon that started with the launch of satellite altimetry, but rather a feature that was already under way in the 1960s (Fig. 2b), a finding that contrasts with simple latitudinal averaging of tide-gauge records pointing towards an inflexion point in GMSL rates at the beginning of the $1990 \mathrm{~s}^{26}$.

We can also obtain the acceleration by fitting a quadratic curve to the 25-year window from 1991-2015, as recently done by ref. ${ }^{4}$. Our estimate of $0.09 \pm 0.02 \mathrm{~mm} \mathrm{yr}^{-2}$ for 1991-2015 agrees with that study's value of $0.097 \pm 0.03 \mathrm{~mm} \mathrm{yr}^{-2}$ for 1993-2017 (Fig. 2c). After adjusting the record for the damping effect of the Mount Pinatubo volcanic eruption in 1991 (ref. ${ }^{27}$ ), as well as $\mathrm{ENSO}^{28}$ and natural variability of individual sea-level contributors from climate simulations with natural forcing only, ref. ${ }^{4}$ attributed this acceleration to human influences ${ }^{4}$. With the HR we are able to determine whether similar acceleration periods occurred in the early parts of the twentieth century, when anthropogenic forcing of sea level was much less pronounced ${ }^{29-31}$. Fig. $2 c$ shows the acceleration coefficients (that is, twice the quadratic term in a second-order least squares fit) calculated over every 25 -year period in the record. Two features are striking in this plot. First, we see similarly high accelerations in the 1930 s, a period that was characterized by strong natural warming in the higher latitudes of the Northern Hemisphere leading, for instance, to accelerated ice melt ${ }^{29,30}$. This melting has largely been attributed to a delayed response to the Little Ice Age ${ }^{29}$ and to a negative phase of the North Atlantic Oscillation ${ }^{32}$, thus providing evidence that natural forcing can in principle induce GMSL accelerations comparable to those over the short altimeter record. Second, after a reversal to decelerating rates in the 1950s 
Table 1 | Average nonlinear trends (derived from an SSA with an embedding dimension of 10 years) and acceleration coefficients, their 1 s.e.m. (based on the formal uncertainties in the HR), and correlations for satellite altimetry and the HR for different periods

\begin{tabular}{|c|c|c|c|c|c|}
\hline \multirow[t]{3}{*}{ Region } & \multicolumn{3}{|c|}{ Average nonlinear trend \pm 1 s.e.m. $\left(\mathrm{mm} \mathrm{yr}^{-1}\right)$} & \multirow{3}{*}{$\begin{array}{l}\text { Acceleration } \pm 1 \text { s.e.m. }\left(\mathrm{mm} \mathrm{yr}^{-2}\right) \\
1968-2015 \\
\text { HR }\end{array}$} & \multirow{3}{*}{$\begin{array}{l}\text { Correlation } \\
1993-2015 \\
\text { Altimetry versus HR }\end{array}$} \\
\hline & \multicolumn{2}{|l|}{ 1993-2015 } & \multirow{2}{*}{$\begin{array}{l}1900-2015 \\
\text { HR }\end{array}$} & & \\
\hline & Altimetry $^{\mathrm{a}}$ & HR & & & \\
\hline South Atlantic & $2.7 \pm 0.5$ & $2.5 \pm 0.3$ & $1.6 \pm 0.5$ & $0.06 \pm 0.01$ & 0.87 \\
\hline Indo-Pacific & $3.5 \pm 0.4$ & $3.3 \pm 0.3$ & $1.6 \pm 0.5$ & $0.07 \pm 0.01$ & 0.97 \\
\hline East Pacific & $1.0 \pm 1.9$ & $1.3 \pm 0.7$ & $1.5 \pm 0.7$ & $0.01 \pm 0.04$ & 0.98 \\
\hline Subpolar North Atlantic & $2.3 \pm 0.6$ & $2.2 \pm 0.3$ & $1.4 \pm 0.6$ & $0.06 \pm 0.01$ & 0.92 \\
\hline Subtropical North Atlantic & $2.6 \pm 0.7$ & $3.0 \pm 0.4$ & $1.5 \pm 0.5$ & $0.07 \pm 0.01$ & 0.91 \\
\hline Northwest Pacific & $3.2 \pm 0.6$ & $3.0 \pm 0.3$ & $1.6 \pm 0.6$ & $0.07 \pm 0.02$ & 0.92 \\
\hline Arctic Ocean $\left(>66^{\circ} \mathrm{N}\right)$ & $0.2 \pm 6.3$ & $1.1 \pm 0.8$ & $1.0 \pm 0.8$ & $0.01 \pm 0.02$ & 0.91 \\
\hline Southern Ocean ( $\left.>66^{\circ} \mathrm{S}\right)$ & $1.8 \pm 0.7$ & $1.7 \pm 0.4$ & $1.6 \pm 0.6$ & $-0.01 \pm 0.01$ & 0.75 \\
\hline Global & $2.8 \pm 0.1$ & $2.8 \pm 0.3$ & $1.6 \pm 0.4$ & $0.06 \pm 0.01$ & 0.95 \\
\hline
\end{tabular}

Uncertainties are based on the noise from a first-order autoregressive process (AR1) only.

and 1960s, we observe a plateau in the acceleration coefficients that was established after $\sim 1967$ and has persisted to the present day. Although the magnitudes of the acceleration coefficients are not significantly larger than those seen in the 1930s, the persistence is indeed unprecedented over the twentieth century in a way that has not been recognized before ${ }^{33}$. There are several reasons for this: first, the persistence of the acceleration is more pronounced than in former RSOI and virtual station reconstructions ${ }^{33}$, largely because low-frequency variations in such reconstructions are affected by spurious signals stemming from sampling issues and do not represent the true $\mathrm{GMSL}^{18}$, as indicated by their low correlation with satellite altimetry ${ }^{17}$ after removal of the trend. Second, although in the HR the acceleration is essentially determined by the $\mathrm{KS}^{12}$, the persistence of the acceleration has not been assessed before ${ }^{12,14}$ and becomes more apparent in the HR due to the temporal extension here by five further years relative to past studies ${ }^{12,14}$.

\section{The role of the Southern Hemisphere and wind forcing}

To investigate the origin of this sustained acceleration, we calculated similar 25-year moving accelerations for eight basin-scale regions of spatially coherent variability ${ }^{23}$ (see Methods) and weighted them according to their area (Fig. 3a). The North Atlantic, Arctic (north of $67^{\circ} \mathrm{N}$ ), and Southern Ocean (south of $67^{\circ} \mathrm{S}$ ) together only explain $\sim 3 \%$ of the variance in the time series of moving acceleration coefficients in GMSL (see Methods). Accordingly, the remainder of the ocean is responsible for the vast majority of the acceleration patterns in GMSL ( 97\%), whereby the southern regions (Indo-Pacific/South Atlantic) are the dominant drivers of the deceleration in the 1950s and the plateau since the late 1960s $(\sim 76 \%)$. The North Pacific contributes to the decadal variability $(\sim 21 \%)$ but is not the major driver of the persistent acceleration in the last decades (Fig. 3a).

The dominant role of the southern regions is further illustrated by the acceleration coefficients derived over the period 1968-2015 in Fig. 3b. While significant positive accelerations are a common feature over many parts of the global ocean (except coastal areas in higher latitudes of the Atlantic and Pacific that are also known to be heavily influenced by natural modes of variability), larger values are, in agreement with ref. ${ }^{26}$, confined to the tropics (particularly in the Atlantic and Indian Oceans) and the Southern Ocean (Fig. 3c). What is striking is a dipole-like pattern with acceleration/deceleration hotspots north/south of $50^{\circ} \mathrm{S}$ in the South Pacific, resembling (although much more pronounced) the dynamic (that is, jointly determined by ocean density and circulation) sea-level changes predicted by climate models over the twentieth (Supplementary Fig. 6) and twenty-first centuries ${ }^{34-36}$ in response to an intensification and a latitudinal shift of Southern Hemispheric westerlies, with the former also being observed since the $1950 \mathrm{~s}^{36}$. The observed intensification coincides with a positive shift in the Southern Annular Mode and has previously been associated with increasing concentrations of ozone-depleting and greenhouse gases ${ }^{37}$.

Using an eddy-permitting $\left(1 / 4^{\circ}\right)$ global ocean model, ref. ${ }^{36}$ demonstrated that changes in the intensity and position of the westerlies have very different imprints in regional and GMSL. The regional sea-level response to intensifying westerlies largely reflects an increased sea-surface gradient across the Antarctic Circumpolar Current associated with a deepening of the thermocline to the north. However, through its effect on ocean circulation and rates of ocean heat uptake, westerly wind intensification also has an effect on GMSL. Modelling studies ${ }^{34,36}$ suggest that a westerly wind intensification of $\sim 15 \%$ results in a GMSL rise of $\sim 40 \mathrm{~mm}$ over 70 years, due to increased ocean heat uptake in the Southern Hemisphere. Ref. ${ }^{36}$ also showed that a southward movement of westerly winds, in contrast to a strengthening, causes GMSL to fall.

An analysis of twentieth-century reanalysis winds ${ }^{38}$ indeed points to increased and accelerated westerlies along $40-60^{\circ} \mathrm{S}$ since 1968 but no poleward migration ${ }^{39}$ (Supplementary Figs. 6 and 7). To further assess the role of wind forcing, we performed a maximum covariance analysis (MCA) between detrended and GIA-corrected sea-level fields (corrected for present-day mass contribution from ref. ${ }^{40}$ to isolate dynamic and global steric components) and twentieth-century reanalysis wind stress curl (WSC) over the southern regions. The MCA extracts the respective spatial patterns and time series that explain the most cross covariance between two scalar fields (see Methods). The first coupled mode shows strong positive/negative values in the Indo-Pacific, which are very similar to sea-level imprint of ENSO. Indeed, its principal component (PC) is dominated by inter-annual variability and significantly correlated with ENSO $(r=0.87)$, but it shows little evidence for a significant acceleration since 1968 (Supplementary Fig. 8). However, the second and third modes (Fig. 4c,f) are broadly consistent with the spatial acceleration pattern in Fig. $3 \mathrm{~b}$, show significantly correlated PCs $\left(r_{\mathrm{PC} 2}=0.76\right.$ and $r_{\mathrm{PC} 3}=0.81$; Fig. $\left.4 \mathrm{a}, \mathrm{d}\right)$, and explain (integrated over the oceans, see Methods) a significant portion of the interannual and long-term variations in regional sea level $(r=0.90)$ and GMSL $(r=0.75)$ (Fig. $4 \mathrm{~g}-\mathrm{i})$. The second mode indicates a hemispheric-wide intensification of the westerlies with particularly large increases since the 1960s south of Australia (Fig. $4 \mathrm{~b}$ and 

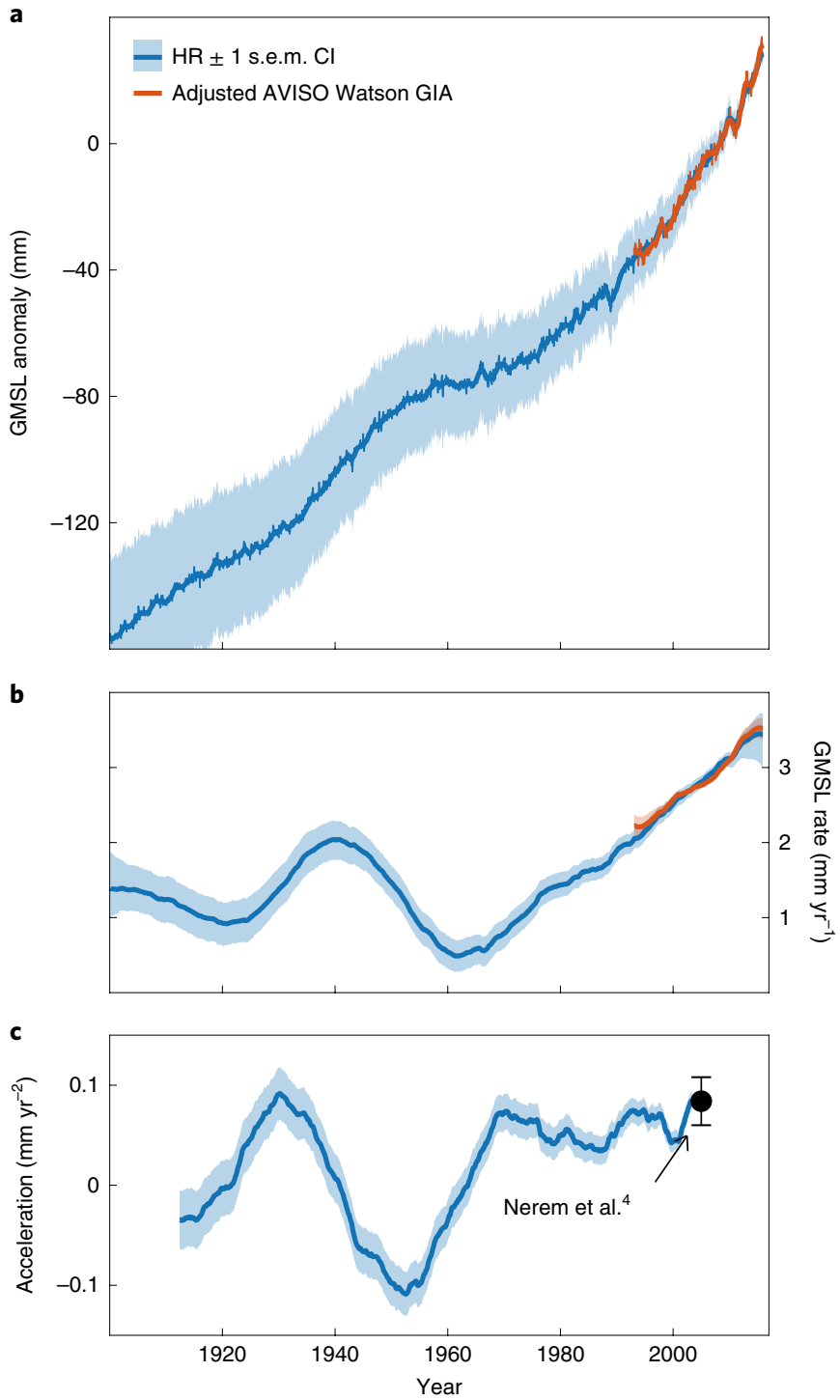

Fig. 2 | GMSL from the HR and satellite altimetry during 1900-2015.

a, Time series of GMSL from the HR and AVISO satellite altimetry adjusted for the lower (GIA-based, $1.1 \mathrm{~mm} \mathrm{yr}^{-1}$ ) drift correction from ref. ${ }^{46}$. Thin lines show monthly means, while tick lines mark annual averages. $\mathbf{b}$, Rates of GMSL rise as derived from an SSA with an embedding dimension of 10 years. c, Acceleration coefficients as derived from 25-year moving quadratic fits. Also shown, as a black error bar, is the recent estimate from ref. ${ }^{4}$ over the period $1993-2018$. All shadings represent the \pm 1 s.e.m. pointwise uncertainties.

Supplementary Fig. 7). In contrast, WSC mode 3 is characterized by a north-south tripole in the South Pacific, which we interpret as a basin-scale $\left(\sim 78^{\circ} \mathrm{E}-140^{\circ} \mathrm{E}\right)$ equatorward migration (instead of a poleward shift as projected for the future ${ }^{36,39}$ ) of the westerlies (Fig. 4e). This is supported by an analysis of the position of the Southern Hemispheric westerlies showing a distinct positive trend since the 1970s (Fig. 4d and also visible in the ERA20C reanalysis product in Supplementary Fig. 7). Both the intensification as well as the equatorward migration may well explain the dipole-like sea-level pattern in South Pacific (Fig. 4c,f and Supplementary Fig. 6a) but also increased ocean heat uptake due to upwelling of cold and dense waters from the mid-layers, thus contributing to the accelerated rates in GMSL since the $1960 \mathrm{~s}^{36}$. In accordance with this hypothesis

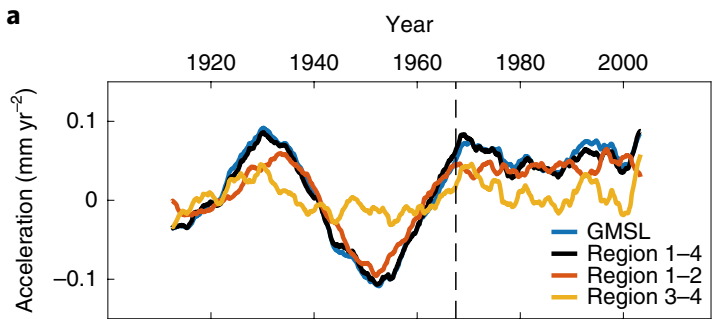

b
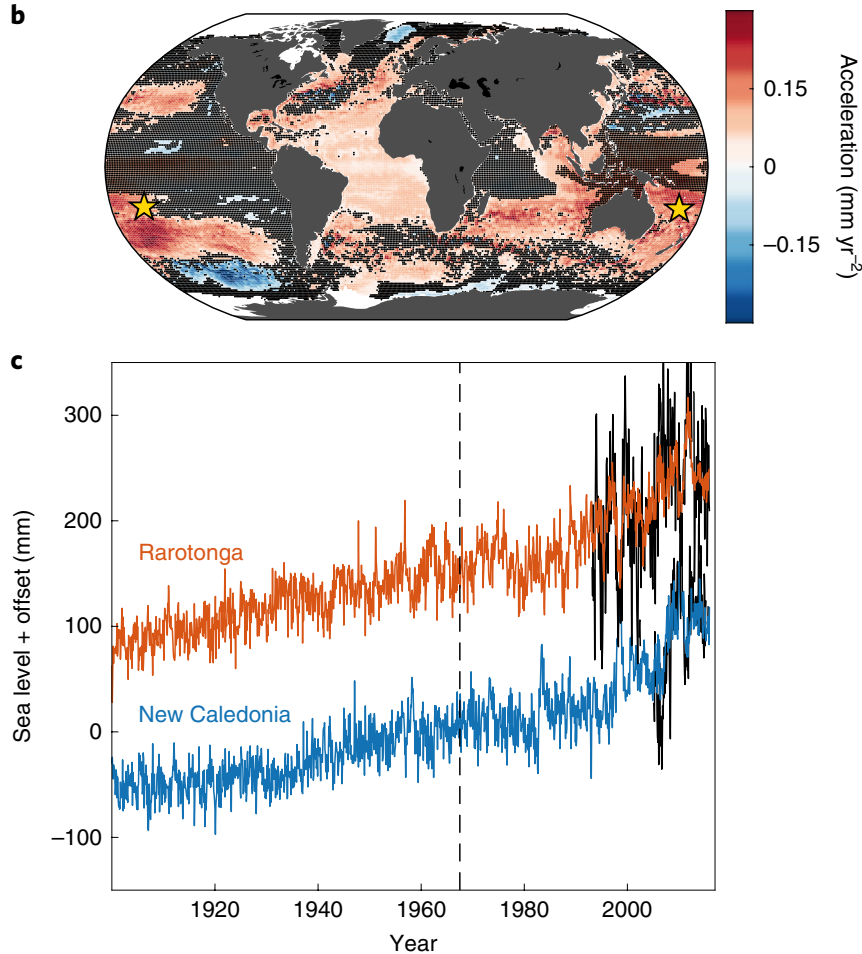

Fig. 3 | Regional origin of the GMSL acceleration plateau since the 1960s. a, Acceleration coefficients as derived from 25-year moving quadratic fits of GMSL and for different ocean basin averages (Region 1: South Atlantic; Region 2: Indo-Pacific; Region 3: East Pacific; Region 4: Northwest Pacific). Each basin estimate has been weighted by its surface area to compute its total GMSL contribution. The vertical black dotted line marks the starting period of the acceleration plateau in 1968. b, GIA-corrected relative sealevel trend acceleration from 1968-2015 at each grid point. Non-significant differences are marked by black stippling. The yellow stars mark the Pacific island stations of New Caledonia and Rarotonga. c, GIA-corrected relative sea-level time series averaged from grid points around New Caledonia (blue) and Rarotonga (red) and nearby tide-gauge records from the two islands (black).

both modes are positively correlated with sea level over the majority of the global ocean (Fig. 4h,i).

The observed pattern in the Indo-Pacific/South Atlantic regions is indicative of a thermosteric initiation of the GMSL acceleration plateau in the 1960s. Unfortunately, due to sparse observational data, regional and global steric sea-level estimates are highly uncertain, thus hampering a direct assessment of the in-situ data ${ }^{1,3,41}$. However, an alternative approach is to assess the mass budget from independent reconstructions of glaciers ${ }^{42}$, the Greenland ${ }^{43}$ and Antarctic ice sheets ${ }^{40}$, and terrestrial water storage ${ }^{40}$, and to interpret the differences between the sum of these contributions and the HR GMSL as an indirect estimate of the steric component (reasonably assuming a minor influence of the interannual-to-decadal variability in the global water cycle on longer-term accelerations in 


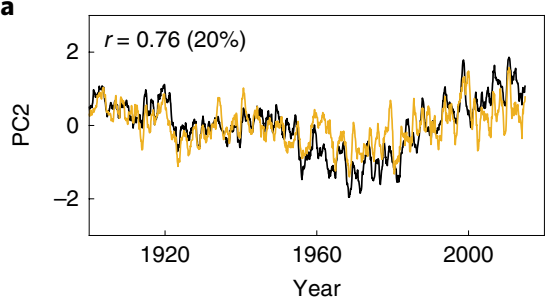

d

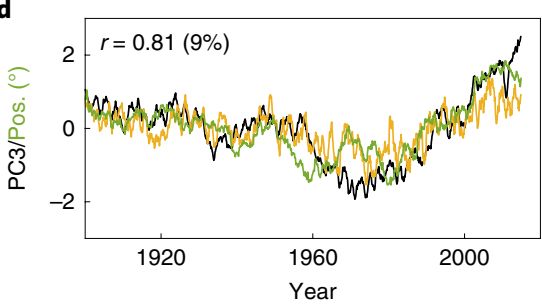

g

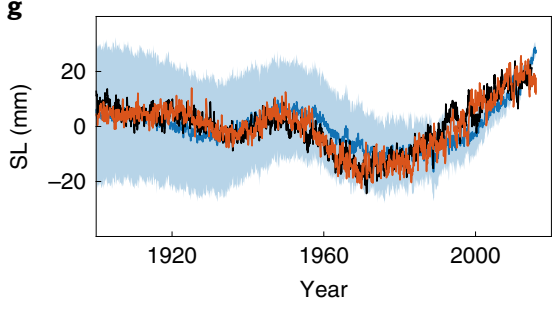

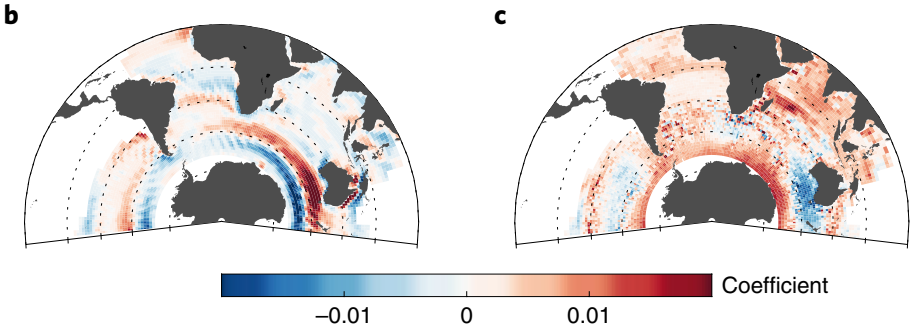

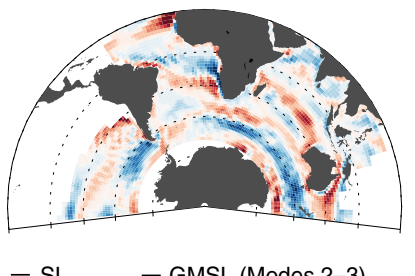

f

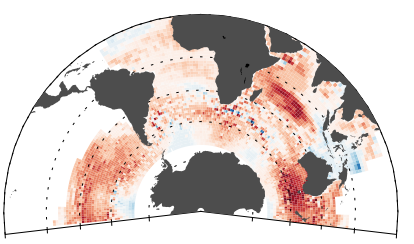

- SL - GMSL (Modes 2-3)

- WSC - SL (Indo-Pacific + South Atlantic)

= GMSL $-\mathrm{SH}$ Westerlies Position (South Pacific)

h

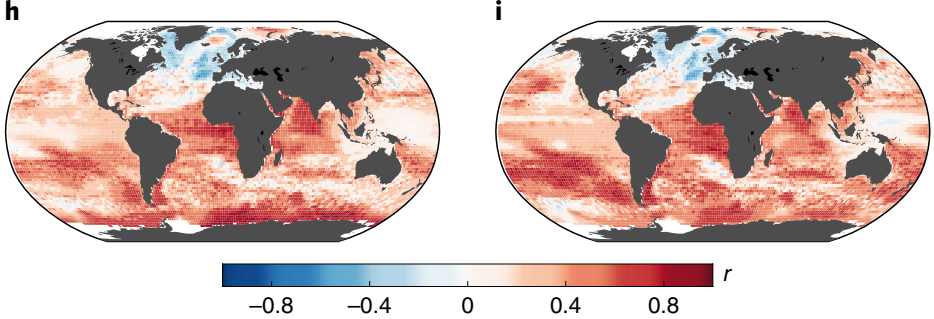

Fig. 4 | Role of Southern Hemispheric wind forcing. Results of an MCA between detrended sea level (SL, corrected for the contributions from GIA and present-day mass contribution, and therefore jointly determined by ocean density and circulation) over Regions 1 (South Atlantic) and 2 (Indo-Pacific) and WSC from the twentieth-century reanalysis. a-c, Monthly time series (for illustration purposes shown as a 12-month moving average) of the coupled PC2 (a; explaining 20\% of their squared covariance) and their corresponding EOF modes for WSC (b) and SL (c). d-f, Coupled PC3 (d; explaining $9 \%$ of their squared covariance) and their corresponding EOF modes for WSC (e) and SL (f). The 10-year smoothed time series of the position of the Southern Hemispheric Westerlies (green) averaged over an area between 78 and $140^{\circ} \mathrm{W}$ are overlaid. $\mathbf{g}$, Time series of detrended GMSL, SL averaged over Regions 1 and 2, and the contributions from MCA Modes 2 and 3 to GMSL (the PCs have first been regressed against each grid point time series from the SL field. Then, in a second step, the resulting time series have been averaged over the global ocean). $\mathbf{g}$,h, Global correlation maps correlations between PC2 (h) and PC3 (i) and SL at each grid point.

GMSL $^{19}$ ). Indeed, the acceleration plateau since the 1960s is difficult to reconcile with the temporal progression of individual mass components, in particular those from ice-melt (Supplementary Fig. 9). While ice-melt significantly contributed to the high rates obtained in the 1930s as well as the recent altimeter period, it had zero to negative contributions to the acceleration coefficients between the 1940s and the early 1990s (Supplementary Fig. 9). Only the contribution of terrestrial water storage shows an acceleration starting in the 1960s, but its magnitude is an order of magnitude smaller than that obtained from GMSL and only a dominant contributor in the 1980s (Supplementary Fig. 9) ${ }^{44}$. Consequently, the (steric) residual explains nearly entirely the low rates and negative acceleration coefficients in the 1960s as well as the start of the acceleration plateau thereafter. This is also in good agreement with simulated thermosteric GMSL from climate models ${ }^{30,44}$. Only since the 1990s has ice (in particular through accelerated mass loss in Greenland and Antarctica) again dominated the GMSL acceleration. As a validation we compared the indirect steric estimate from the residual to two observational products ${ }^{1,3}$ over the altimetry era (Supplementary Fig. 9a,b). With an average rate of about $0.9 \pm 0.4 \mathrm{~mm} \mathrm{yr}^{-1}$ the residual agrees well with the two observation-based time series showing rates of about $0.9 \pm 0.4 \mathrm{~mm} \mathrm{yr}^{-1}$ and $1.3 \pm 0.6 \mathrm{~mm} \mathrm{yr}^{-1}$, respectively. In addition, all three time series show a decreasing tendency of steric rates with a minimum in 2011 and a slight recovery thereafter
(Supplementary Fig. 9b). Altogether, this supports our hypothesis that thermal expansion (likely linked to changing Southern Hemispheric westerlies) has been the major driving force behind the start of the GMSL acceleration since the late 1960s.

This has important implications. Over the recent altimetry period the observed GMSL acceleration has mainly been attributed to accelerated mass loss of the ice sheets in Greenland and Antarctica without any significant contribution from thermal expansion ${ }^{1-3}$. Refs. ${ }^{27,45}$ argue that the Mount Pinatubo volcanic eruption in 1991 led to a decrease in global ocean heat uptake and mean steric sea level during the early years of satellite altimetry. This suggests that the recent deceleration in steric rates (Supplementary Fig. 9) is a temporary and transient phenomenon. As climate models ${ }^{33}$ consistently project increasing rates of thermosteric GMSL rise under sustained greenhouse gas emissions, it is likely that the detected steric acceleration over the twentieth century as a whole will therefore emerge again, leading (together with accelerated mass loss) to a further steepening of the rates of GMSL rise. Our results further suggest that changes in the intensity and position of Southern Hemispheric westerlies play a critical role in controlling the magnitude of this acceleration, whereby climate models consistently project, in addition to a further intensification $^{39}$ and different to observations over the last decades, a poleward migration $^{36,39}$. 


\section{Online content}

Any methods, additional references, Nature Research reporting summaries, source data, statements of code and data availability and associated accession codes are available at https://doi.org/10.1038/ s41558-019-0531-8.

Received: 20 March 2019; Accepted: 14 June 2019;

Published online: 5 August 2019

\section{References}

1. Cazenave, A. et al. Global sea-level budget 1993-present. Earth Syst. Sci. Data 10, 1551-1590 (2018).

2. Dieng, H. B., Cazenave, A., Meyssignac, B. \& Ablain, M. New estimate of the current rate of sea level rise from a sea level budget approach. Geophys. Res. Lett. 44, 3744-3751 (2017).

3. Chen, $X$. et al. The increasing rate of global mean sea-level rise during 1993-2014. Nat. Clim. Change 7, 492-495 (2017).

4. Nerem, S. et al. Climate change driven accelerated sea level rise detected in the altimeter era. Proc. Natl Acad. Sci. USA 115, 2022-2025 (2018).

5. Bamber, J. L., Westaway, R. M., Marzeion, B. \& Wouters, B. The land ice contribution to sea level during the satellite era. Environ. Res. Lett. 13, 063008 (2018)

6. Shepherd, A. et al. Mass balance of the Antarctic ice sheet from 1992 to 2017. Nature 558, 219-222 (2018).

7. Frederikse, T., Riva, R. E. M. \& King, M. Ocean bottom deformation due to present-day mass redistribution and its impact on sea level observations. Geophys. Res. Lett. 44, 306-3012 (2017).

8. Santamaria-Gomez, A. et al. Uncertainty of the 20th century sea-level rise due to vertical land motion. Earth Planet. Sci. Lett. 473, 24-32 (2017).

9. Lickley, M. J., Hay, C. C., Tamisiea, M. E. \& Mitrovica, J. X. Bias in estimates of global mean sea level change inferred from satellite altimetry. J. Clim. 31, 5263-5271 (2018)

10. Church, J. A. \& White, N. J. Sea-level rise from the late 19th to the early 21 st century. Surv. Geophys. 32, 585-602 (2011).

11. Meyssignac, B., Becker, M., Llovel, W. \& Cazenave, A. An assessment of two-dimensional past sea level reconstructions over 1950-2009 based on tide-gauge data and different input sea level grids. Surv. Geophys. 33, 945-972 (2012).

12. Hay, C. H., Morrow, E., Kopp, R. E. \& Mitrovica, J. X. Probabilistic reanalysis of twentieth-century sea level rise. Nature 517, 481-484 (2015).

13. Kopp, R. E. et al. Temperature-driven sea-level variability in the Common Era. Proc. Natl Acad. Sci. USA 113, 1434-1441 (2016).

14. Hay, C. H., Morrow, E. D., Kopp, R. E. \& Mitrovica, J. X. On the robustness of Bayesian fingerprinting estimates of global sea level change. J. Clim. 30, 3025-3038 (2017).

15. Mitrovica, J. X., Tamisiea, M. E., Davis, J. L. \& Milne, G. A. Recent mass balance of polar ice sheets inferred from patterns of global sea-level change. Nature 409, 1026-1029 (2001)

16. Wenzel, M. \& Schroeter, J. Reconstruction of regional mean sea level anomalies from tide gauges using neural networks. J. Geophys. Res. 115, C08013 (2010).

17. Dangendorf, S. et al. Detecting anthropogenic footprints in sea level rise. Nat. Commun. 6, 7849 (2015).

18. Calafat, F. M., Chambers, D. P. \& Tsimplis, M. N. On the ability of global sea level reconstructions to determine trends and variability. J. Geophys. Res. 119 1572-1592 (2014).

19. Hamlington, B. D. et al. Separating decadal global water cycle variability from sea level rise. Sci. Rep. 7, 995 (2017).

20. Mu, D., Yan, H. \& Feng, W. Assessment of sea level variability derived by EOF reconstruction. Geophys. J. Int. 214, 79-87 (2018).

21. Dangendorf, S. et al. Reassessment of 20th century global mean sea level rise. Proc. Natl Acad. Sci. USA 114, 5946-5951 (2017).

22. Carson, M. et al. Regional sea level variability and trends, 1960-2007: a comparison of sea level reconstructions and ocean syntheses. J. Geophys. Res. 122, 9068-9091 (2017).

23. Thompson, P. R. \& Merrifield, M. A. A unique asymmetry in the pattern of recent sea level change. Geophys. Res. Lett. 41, 7675-7683 (2014).

24. Calafat, F. M. \& Chambers, D. Quantifying recent acceleration in sea level unrelated to internal climate variability. Geophys. Res. Lett. 40, 3661-3666 (2013).

25. Thompson, P. R., Merrifield, M. A., Wells, J. R. \& Chang, C. M. Wind-driven coastal sea level variability in the Northeast Pacific. J. Clim. 27, 4733-4751 (2014)

26. Merrifield, M. A., Merrifield, S. T. \& Mitchum, G. T. An anomalous recent acceleration of global sea level rise. J. Clim. 22, 5772-5781 (2009).

27. Fasullo, J. T., Nerem, R. S. \& Hamlington, B. Is the detection of accelerated sea level rise imminent? Sci. Rep. 6, 31245 (2016).

28. Cazenave, A. et al. The rate of sea-level rise. Nat. Clim. Change 4, 358-361 (2014).
29. Marzeion, B., Cogley, J. G., Richter, K. \& Parkes, D. Attribution of global glacier mass loss to anthropogenic and natural causes. Science 345, 919-921 (2014).

30. Slangen, A. B. A. et al. Anthropogenic forcing dominates global mean sea-level rise since 1970. Nat. Clim. Change 6, 701-705 (2016).

31. Marcos, M. et al. Internal variability versus anthropogenic forcing on sea level and its components. Surv. Geophys. 38, 329-348 (2017).

32. Chylek, P., Box, J. E. \& Lesins, G. Global warming and the Greenland ice sheet. Climatic Change 63, 201-221 (2004).

33. Church, J. A. et al. in Climate Change 2013: The Physical Science Basis (eds Stocker, T. F. et al.) Ch. 13 (IPCC, Cambridge Univ. Press, 2013).

34. Bouttes, N. J., Gregory, J. M., Kuhlbrodt, T. \& Suzuki, T. The effect of windstress change on future sea level change in the Southern Ocean. Geophys. Res. Lett. 39, L23602 (2012).

35. Slangen, A. B. A., Church, J. A., Zhang, X. \& Monselesan, S. P. The sea level response to external forcings in historical simulations of CMIP5 climate models. J. Clim. 28, 8521-8539 (2015).

36. Francombe, L. E. et al. Sea level changes forced by Southern Ocean winds. Geophys. Res. Lett. 40, 5710-5715 (2013).

37. Thompson, D. W. J. et al. Signatures of the Antarctic ozone hole in Southern Hemispheric surface climate change. Nat. Geosci. 4, 741-749 (2011).

38. Compo, G. P. et al. The twentieth century reanalysis project. Q. J. R. Meteorol. Soc. 137, 1-28 (2011)

39. Swart, N. C. \& Fyfe, J. C. Observed and simulated changes in the Southern Hemisphere surface westerly wind-stress. Geophys. Res Lett. 39, L16711 (2012).

40. Frederikse, T., Jevrejeva, S., Riva, R. E. M. \& Dangendorf, S. A consistent sea-level reconstruction and its budget on basin and global scales over 1958-2014. J. Clim. 31, 1267-1280 (2018).

41. Abraham, J. P. et al. A review of global ocean temperature observations: implications for ocean heat content estimates and climate change. Rev. Geophys. 51, 450-483 (2013).

42. Marzeion, B., Leclercq, P. W., Cogley, J. G. \& Jarosch, A. H. Brief communication: global reconstructions of glacier mass change during the 20th century are consistent. Cryosphere 9, 2399-2404 (2015).

43. Kjeldsen, K. K. et al. Spatial and temporal distribution of mass loss from the Greenland ice sheet since AD 1900. Nature 528, 396-400 (2015).

44. Church, J. A., Monselesan, D., Gregory, J. M. \& Marzeion, B. Evaluating the ability of process based models to project sea-level change. Environ. Res. Lett. 8, 014051 (2013).

45. Church, J. A., White, N. J. \& Arblaster, J. M. Significant decadal-scale impact of volcanic eruptions on sea level and ocean heat content. Nature 438, $74-77$ (2005).

46. Watson, C. S. et al. Unabated global mean sea-level rise over the satellite altimeter era. Nat. Clim. Change 5, 565-568 (2015).

\section{Acknowledgements}

We are grateful to the International Space Science Institute (Bern, Switzerland) for support of the International Team 'Towards a Unified Sea Level Record', the University of Siegen for the funding of the interdisciplinary research project 'PEPSEA', and the Bundesministerium für Bildung und Forschung for the funding of the project 'MSL Absolut' (funding number: 03KIS116). S.D further acknowledges a visiting scientist fellowship of the University of the Balearic Islands and the FOKOS of the University of Siegen for funding a research stay at the Boston College. C.G.P. was supported by NSF awards OCE-1558966 and OCE-1834739. We acknowledge T. Wahl and R. Gehrels for providing comments on an earlier version of the manuscript.

\section{Author contributions}

S.D. designed and performed the research and wrote the first draft of the paper. C.H. and F.M.C contributed their results/codes for the Kalman Smoother and the RSOI approach, respectively. C.G.P. helped with the assessment of the wind forcing. K.B. contributed to the coding of the statistical analysis tools. All authors shared ideas and contributed to the writing of the manuscript.

\section{Competing interests}

The authors declare no competing interests.

\section{Additional information}

Supplementary information is available for this paper at https://doi.org/10.1038/ s41558-019-0531-8.

Reprints and permissions information is available at www.nature.com/reprints. Correspondence and requests for materials should be addressed to S.D.

Peer review information: Nature Climate Change thanks Graham Quartly and the other, anonymous, reviewer(s) for their contribution to the peer review of this work.

Publisher's note: Springer Nature remains neutral with regard to jurisdictional claims in published maps and institutional affiliations.

(c) The Author(s), under exclusive licence to Springer Nature Limited 2019 


\section{Methods}

Hybrid sea-level reconstruction. The KS and RSOI techniques belong to the most prominent sea-level reconstruction approaches ${ }^{10,12,22}$. Although both have been designed to reconstruct twentieth-century global and regional sea-level changes, they have their distinct advantages and shortcomings. The KS used here fits a series of theoretically known cryospheric fingerprints (two ice sheets, 18 major glacier regions and GIA from 161 Earth rheological models) and dynamic sea surface height patterns (six global climate models) to a particular set of tide-gauge records (622 in total) to identify an optimal combination of different sea-level contributors explaining the spatial variations seen within the measurements (see ref. ${ }^{12}$ and ref. ${ }^{14}$ for details). The KS naturally accommodates spatial and temporal sea-level changes in the sparse and gappy set of tide-gauge records, takes the uncertainty/bias in GIA and ocean dynamics specifically into account, and allows for a robust uncertainty propagation ${ }^{12}$. The KS has been demonstrated to provide robust long-term changes of sea-level on multidecadal time scales ${ }^{14}$. However, mainly due to smoothing and the fact that historical global climate simulations (not initialized from observations) are used for the description of ocean dynamics, the KS only provides a smooth description of longterm changes in sea level without realistic interannual variability, currently preventing a direct comparison to observations from the short satellite altimeter record ${ }^{12,17}$. The RSOI, in turn, decomposes satellite altimetry into a number of EOFs with principle components (PCs) describing the temporal behaviour of each spatial pattern. These PCs are then estimated by fitting a weighted sum of EOFs to the existing tide-gauge records, resulting in a sea-level reconstruction having the same temporal extent as tide gauges and the same spatial resolution as satellite altimetry ${ }^{10,47,48}$. This assumes that the EOFs from satellite altimetry are stationary in time, which is speculative given the significant multi-decadal variability seen in tide-gauge records around the world ${ }^{49-56}$. To account for long-term spatially uniform sea-level changes (that is, trends) ref. ${ }^{47}$ further modified the initial approach by adding an artificial uniform EOF (the so-called EOF0). Theoretical analysis of the RSOI equations along with sensitivity experiments with ocean reanalysis data ${ }^{18}$ used as surrogate fields with known GMSL have shown that the use of the EOF0 stabilizes the reconstruction of long-term trends, but hinders a realistic reconstruction of interannual-to-decadal variability (see also Supplementary Fig. 5). The opposite is true when omitting the $\mathrm{EOF0}^{18}$; the variability is reconstructed much more realistically but the trends are not properly captured ${ }^{54}$.

Given these very different strengths and weaknesses of the KS and RSOI approaches, we bring together both in the HR by applying them only at those time scales where they have particular well-proven performance. The KS provides smooth relative sea-level (RSL) predictions at a global grid $\left(\right.$ here $1^{\circ} \times 1^{\circ}$ ), a mean GIA field and a local RSL prediction at 622 tide-gauge locations ${ }^{12}$. Here we start with the local tide-gauge predictions at 617 sites (five sites from Hudson Bay have been omitted as the surroundings are not well resolved by satellite altimetry), which accurately mimic the long-term changes seen in observations (Supplementary Fig 1a). These (as well as the whole global KS RSL field) are low-pass filtered using an SSA $^{55}$ with an embedding dimension of 15 years, thus retaining only the lowfrequency signal, which is hardly resolvable by EOFs from the 23 years of satellite altimetry. The definition of the embedding dimension is based on a compromise between the strengths/weaknesses of the KS and the resolvability of signals with the EOF from a 23-year record and may change in the future when longer altimetry data becomes available. The low-pass filtered KS prediction is then removed from the tide-gauge records, leaving a nearly trend-free residual series only containing high-frequency variability at periods below $\sim 15$ years (Supplementary Fig. 1b). Given the absence of any long-term trends in the residual series (Supplementary Fig. 1b), the use of the EOF0, as established by ref. ${ }^{47}$, is no longer necessary, consequently allowing for an improved reconstruction of the interannual variability up to 15 years $^{18}$. However, once applying the RSOI approach to the nonlinearly detrended tide-gauge records, we still recognized significant drifts introduced through the large number of data gaps and the decreasing number of available tidegauge records back in time. Therefore, we follow ref. ${ }^{16}$, and implement an iterative two-step gap-filling algorithm based on stepwise regression models using (similarly high-pass filtered) wind stress and sea-level pressure (SLP) from the twentieth c-entury reanalysis project ${ }^{38}$, sea surface temperature (SST) from the HadSST3 dataset (https://www.metoffice.gov.uk/hadobs/hadsst3/) (selected from the 50 closest grid points around each site), and neighbouring tide gauges as predictors. The stepwise algorithm is similar to that used in ref. ${ }^{56}$ and ref. ${ }^{40}$ and only includes predictors that contribute significantly to the explained variability (that is, $P<0.05$ ).

(1) In the first step, only wind stress, SLP and SST are used in the regression. This first step already leads to a good performance at most locations, expressing itself in a global median correlation of $r=0.76$ between individual tide-gauge records and the regression output over their overlapping periods. However, although significantly correlated at most sites, the regression outputs underestimate the variability as they do not account for all processes controlling the local sea-level variability, for instance, due to processes that are remotely forced (sea level is a physical variable that has very large alongshore coherence sometimes extending over thousands of kilometres) and linked with local sea level with a significant temporal lag. Furthermore, the link between the drivers of variability (for example winds) and the local sea level might be nonlinear, which is not accounted for in the linear stepwise regression. We therefore use these provisionally gap-filled tide-gauge records as input for a RSOI reconstruction (including an error matrix accounting for an obser- vational error of $4.5 \mathrm{~cm}\left(\right.$ ref. $\left.\left.{ }^{54}\right)\right)$ together with detrended satellite altimetry fields from AVISO (https://www.aviso.altimetry.fr/) (for details see below). (2) The second step of the gap-filling algorithm includes the same wind stress, SLP and SST predictors as in the first iteration, plus nearby tide gauges in which initial data gaps have been filled with the nearest grid point time series from the above RSOI reconstruction. The performance of the second gapfilling pass significantly increases at individual tide-gauge locations compared with the first step (median correlation of $r=0.98$ from all sites), as it now essentially better exploits the spatial and temporal scales of variability present in the tide-gauge dataset.

Using the complete gap-filled tide-gauge record from the second iteration, the final RSOI reconstruction is initiated and the resulting RSOI fields are finally combined with the low-frequency signal from KS RSL fields.

However, not all tide-gauge records compare well with nearby satellite altimetry either due to signal-processing issues in satellite altimetry near the coast or local issues with individual tide-gauge records (for example, measurement errors or solid earth changes due to groundwater extraction, earthquakes and so on). Therefore, we decided to use only those tide-gauge records in the HR, which show a correlation with nearby satellite altimetry of $r \geq 0.5$. Using an even larger threshold does not alter the results. This procedure leaves 479 tide-gauge records for the HR. To validate the $\mathrm{HR}$ at independent sites, which have not been used in the reconstruction, we further selected 149 tide-gauge records from the Permanent Service for Mean Sea Level (PSMSL) ${ }^{57}$ database fulfilling the same correlation criteria, not being flagged, and providing at least 20 years of data as independent validation sites.

Satellite altimetry data. Here we use sea surface height data from AVISO over the period from 1993 to 2015. The dataset is a merged product of TOPEX/Poseidon and Jason altimeter missions. AVISO products include a number of different geophysical corrections, which are explained in detail on their website (https://www.aviso.

altimetry.fr/en/data/products/ocean-indicators-products/mean-sea-level/processing corrections.html). Here, the record has been corrected for geoid perturbations due to GIA $^{58}$ but not for the inverted barometer effect. However, as satellite altimetry measures sea surface height relative to the Earth's centre of mass, we add an estimate of simultaneous crustal motion from present-day ice-melting ${ }^{7}$ to the field. Satellite altimetry data sets include observations in high latitudes poleward of $65^{\circ} \mathrm{N}$ and $65^{\circ}$ $\mathrm{S}$, but due to seasonal sea-ice coverage this data is gappy and more uncertain than at mid-latitudes ${ }^{59}$. This is particularly true for the ocean interior where the growth of sea ice during winter limits measurements to a few months per year and the TOPEX/ Poseidon and Jason series of missions, which did not cover latitudes higher than $66^{\circ}$ (although European satellites such as ERS already reached higher latitudes but with repeat cycles of $\sim 35$ days). This data sparseness usually prevents the calculation of EOFs, which require complete data sets. To overcome this problem, we applied an Ordinary Kriging algorithm from ref. ${ }^{60}$. Ordinary Kriging is a well-established geophysical interpolation approach, which takes the spatial correlation structure of the underlying dataset into account and has recently been used for temperature reconstructions over the Arctic ${ }^{61}$. Here the Kriging algorithm is used to fill data gaps in the initial altimetry record before calculating the global EOFs. While the inclusion of high latitudes does not alter the global EOFs, it provides the possibility to reconstruct sea level in these areas from the tide-gauge network.

Drift correction. Recent studies suggest significant instrumental drifts of the TOPEX/Poseidon mission (later followed by the Jason missions) leading to an overestimate of GMSL rise before February 1992 of between $0.9 \pm 0.5 \mathrm{~mm} \mathrm{yr}^{-1}$ and $1.5 \pm 1.0 \mathrm{~mm} \mathrm{yr}^{-1}$ (ref. ${ }^{46}$ ). Not considering these drifts in the input altimetry fields for the RSOI reconstruction already yielded significant differences in the order of $\sim 0.7 \mathrm{~mm} \mathrm{yr}^{-1}$ between the resulting GMSL from the HR and uncorrected satellite altimetry from the TOPEX/Poseidon mission. As the drift correction only affects the first $\sim 6$ years of the record, it will obviously change low-frequency signals in satellite altimetry and therefore the EOFs taken for the HR. To test the sensitivity of our HR to these drift estimates, we uniformly corrected the initial satellite altimetry field with two different numbers provided by ref. ${ }^{46}$ before 1999 (when the redundant backup TOPEX-B altimeter was turned on). These authors compared tide-gauge records, corrected either for GIA or vertical land motion measured by the global positioning system, with nearby satellite altimetry data and proposed drift corrections of $1.1 \pm 0.5 \mathrm{~mm} \mathrm{yr}^{-1}$ and $1.5 \pm 0.5 \mathrm{~mm} \mathrm{yr}^{-1}$, respectively. To account for potential biases stemming from any particular selection of tide-gauge records, we reconstructed the GMSL with 500 random samples of $80,160,240,320$ and 400 tide gauges (100 sub-samples for each number) and compared each GMSL reconstruction with that of uncorrected satellite altimetry (Supplementary Fig. 10a,b). We do not find any differences between applying the lower or upper drift correction. In both cases the trend differences between the GMSL from the hybrid reconstruction and uncorrected satellite altimetry increase compared to the initial case of omitting any drift correction $\left(\sim 0.7 \mathrm{~mm} \mathrm{yr}^{-1}\right)$ and scatter between 0.78 and $1.13 \mathrm{~mm} \mathrm{yr}^{-1}(95 \% \mathrm{CI})$ and a central estimate of $0.98 \mathrm{~mm} \mathrm{yr}^{-1}$ (Supplementary Fig. 10c) that is more consistent with the lower end of estimates published in the literature $\left(\sim 0.9 \mathrm{~mm} \mathrm{yr}^{-1}\right)$. Hence, we used our median estimate over all ensemble members $\left(\sim 0.98 \mathrm{~mm} \mathrm{yr}^{-1}\right)$ as a globally uniform correction of the satellite altimetry fields before calculating the EOFs in the hybrid reconstruction. 
Maximum covariance analysis. To evaluate the temporally correlated but spatially heterogeneous signals in sea-level and wind-stress fields, we use MCA, sometimes also referred to as coupled EOF analysis ${ }^{62}$. The MCA is similar to EOF analysis in that they both involve extracting the eigenvectors and eigenvalues of a covariance matrix. The difference is that EOF analysis considers the covariance matrix of a single scalar field, whereas the MCA considers the cross-covariance matrix derived between two scalar fields. Here we apply the MCA to linearly detrended sea-level fields from the southern region including the South Atlantic and the Indo-Pacific, corrected for estimates of the present-day mass contribution from glaciers and ice sheets ${ }^{40,42,43}$, and linearly detrended WSC from twentieth-century reanalysis ${ }^{38}$ over the same region. As an output we get different modes (EOFs), which explain a certain degree of the squared covariance (here the first three EOFs explain 76\%) as well as their temporal amplitudes (PCs). Given the importance of the second and third component for the explanation of the regional and GMSL acceleration since the 1960s, we regressed their sea-level PCs with each grid point globally and averaged the resulting fields (weighted by their latitudes) to estimate their absolute contribution to GMSL (Fig. 4g).

Statistics. All correlations and regressions were performed after removing linear trends. Statistical significance and error estimates are computed using repeated simulations with synthetic time series and the Fourier phase scrambling method described in ref. ${ }^{63}$, thus accounting for the autocorrelation structure inherently present in the observations. For the assessment of the relative contribution of each ocean basin to GMSL, we calculate the explained variance, which provides a measure of the agreement between two variables in terms of both variability and magnitude. The per cent of variance of a variable, $x$, explained by another variable, $y$, is computed as follows:

$$
\text { per cent of variance }=100\left(1-\frac{\operatorname{var}(x-y)}{\operatorname{var}(x)}\right)
$$

where the operator var() denotes variance.

\section{Data availability}

The data that support the findings of this study are available from the corresponding author on request. The GMSL data from the hybrid reconstruction presented in Fig. 2 are provided as Supplementary Data 1.

\section{Code availability}

The codes for the hybrid reconstruction are available from the corresponding author upon request.

\section{References}

47. Church, J. A. et al. Estimates of the regional distribution of sea level rise over the 1950-2000 period. J. Clim. 17, 2609-2625 (2004).

48. Strassburg, M. W., Hamlington, B. D., Leben, R. R. \& Kim, K. Y. A comparative study of sea level reconstruction techniques using 20 years of satellite altimetry data. J. Geophys, Res. 119, 4068-4082 (2014).

49. Woodworth, P. L. et al. Evidence for the accelerations of sea level on multi-decade and century timescales. Int. J. Climatol. 29, 777-789 (2009).

50. Haigh, I. D. et al. Timescales for detecting a significant acceleration in sea level rise. Nat. Commun. 5, 3635 (2014).

51. Visser, H., Dangendorf, S. \& Peterson, A. A review of trend models applied to sea level data with reference to the 'acceleration-deceleration debate'. J. Geophys. Res. 120, 3873-3895 (2015).

52. Miller, L. \& Douglas, B. C. Gyre-scale atmospheric pressure variations and their relation to 19th and 20th century sea level rise. Geophys. Res. Lett. 34, L16602 (2007).

53. Chambers, D. P., Merrifield, M. A. \& Nerem, R. S. Is there a 60-year oscillation in global mean sea level? Geophys. Res. Lett. 18, L18607 (2012).

54. Dangendorf, S. et al. Evidence for long-term memory in sea level. Geophys. Res. Lett. 15, 5530-5537 (2014).

55. Jevrejeva, S., Grinsted, A., Moore, J. C. \& Holgate, S. Nonlinear trends and multiyear cycles in sea level records. J. Geophys. Res. 111, C09012 (2006).

56. Dangendorf, S. et al. Mean sea level variability in the North Sea: processes and implications. J. Geophys. Res. 119, 6820-6841 (2014).

57. Holgate, S. J. et al. New data systems and products at the permanent service for mean sea level. J. Coast. Res. 29, 493-504 (2013).

58. Peltier, W. R. Global glacial isostacy and the surface of the Ice-Age Earth: the ICE5G(VM2) model and GRACE. Ann. Rev. Earth Planet Sci. 32, 111-149 (2004).

59. Quartly, G. D. et al. Retrieving sea level and freeboard in the Arctic: a review of current radar altimetry methodologies and future perspectives. Remote Sens. 11, 881 (2019).

60. Schwanghart, W. \& Kuhn, N. J. A set of Matlab functions for topographic analysis. Environ. Model. Softw. 25, 770-781 (2010).

61. Cowtan, K. \& Way, R. G. Coverage bias in the HadCRUT4 temperature series and its impact on recent temperature trends. Q. J. R. Meteorol. Soc. 140, 1935-1944 (2014).

62. von Storch, H. \& Zwiers, F. M. Statistical Analysis in Climate Research (Cambridge Univ. Press, 1999).

63. Piecuch, C. G. et al. Mechanisms underlying recent decadal changes in subpolar North Atlantic Ocean heat content. J. Geophys. Res. 122, 7181-7197 (2017) 